\title{
Size-Dependent Variability in Flow and Viscoelastic Behavior of Levan Produced by Gluconobacter albidus TMW 2.1191
}

\author{
Christoph S. Hundschell ${ }^{1,2}$, Andre Braun ${ }^{3,4}$, Daniel Wefers ${ }^{5,6}$ (D) , Rudi F. Vogel ${ }^{1}$ \\ and Frank Jakob ${ }^{1, *}$ \\ 1 Chair of Technical Microbiology, Technical University of Munich, Gregor-Mendel-Straße 4, \\ 85354 Freising, Germany; rudi.vogel@wzw.tum.de \\ 2 Department of Food Technology and Food Material Science, Technical University of Berlin, \\ 14195 Berlin, Germany; christoph.hundschell@tu-berlin.de \\ 3 Anton Paar Germany GmbH, Hellmuth-Hirth-Strasse 6, 73760 Ostfildern-Scharnhausen, Germany; \\ andre.braun@anton-paar.com \\ 4 Lehrstuhl für Systemverfahrenstechnik, Technische Universität München, Gregor-Mendel-Straße 4, \\ 85354 Freising, Germany \\ 5 Division of Food Chemistry, Institute of Chemistry, Martin-Luther-University Halle-Wittenberg, \\ 06120 Halle (Saale), Germany; daniel.wefers@chemie.uni-halle.de \\ 6 Department of Food Chemistry and Phytochemistry, Karlsruhe Institute of Technology, \\ 76131 Karlsruhe, Germany \\ * Correspondence: frank.jakob@wzw.tum.de; Tel.: +49-8161-71-5273
}

Received: 9 December 2019; Accepted: 11 February 2020; Published: 14 February 2020

\begin{abstract}
Levan is a fructan-type exopolysaccharide which is produced by many microbes from sucrose via extracellular levansucrases. The hydrocolloid properties of levan depend on its molecular weight, while it is unknown why and to what extent levan is functionally diverse depending on its size. The aim of our study was to gain deeper insight into the size-dependent functional variability of levan. For this purpose, levans of different sizes were produced using the water kefir isolate Gluconobacter albidus TMW 2.1191 and subsequently rheologically characterized. Three levan types could be identified, which are similarly branched, but differ significantly in their molecular size and rheological properties. The smallest levan $\left(<10^{7} \mathrm{Da}\right)$, produced without adjustment of the $\mathrm{pH}$, exhibited Newton-like flow behavior up to a specific concentration of $25 \%(w / v)$. By contrast, larger levans $\left(>10^{8} \mathrm{Da}\right)$ produced at $\mathrm{pH} \geq 4.5$ were shear-thinning, and the levan produced at $\mathrm{pH} 5.0$ showed a gel-like behavior at $5 \%(w / v)$. A third (intermediate) levan variant was obtained through production in buffers at $\mathrm{pH} 4.0$ and exhibited the properties of a viscoelastic fluid up to concentrations of $15 \%$ $(w / v)$. Our study reveals that the rheological properties of levan are determined by its size and polydispersity, rather than by the amount of levan used or the structural composition.
\end{abstract}

Keywords: levan; Gluconobacter; exopolysaccharide; hydrocolloid; molecular weight; rheology

\section{Introduction}

Levan is a $\beta-2,6$-linked, water-soluble fructose polymer which can be branched at position $O 1$. It is produced by bacteria and archaea via secreted or cell-wall anchored, extracellular levansucrases (EC 2.4.1.10) [1-3]. These enzymes use the energy of the glycosidic bond of sucrose for fructose polymerization while glucose is continuously released. Many food-grade starter cultures like Lactobacillus spp. or Gluconobacter spp. produce levans [4-10]. Hence, levan is a natural component of sucrose-containing fermented foods such as sourdough breads [11], kefir [12] or natto [13,14]. Besides 
its prebiotic and health-promoting effects as a source of dietary fiber [15], high-molecular-weight levan can improve the structural properties of foods [16-20] and is a component of microbial biofilms [21-26]. Its functionality as a hydrocolloid is mainly linked to its molecular weight, as high-molecular-weight levan more strongly retards bread staling $[16,17]$. Moreover, its size and functionality can be triggered through control of the fermentation $\mathrm{pH}$ during its production [20]. However, to date, little is known of why, and to what extent, high-molecular-weight levan differs from low-molecular-weight levan regarding its structural and functional properties. The aim of our study was thus to produce levans of different size distributions using the kefir isolate Gluconobacter (G.) albidus TMW 2.1191, which encodes one levansucrase within its genome, and to analyze the linkage types and rheological properties of the isolated levans. The obtained results are correlated to obtain new insights into the size-dependent, functional variability of levan.

\section{Material and Methods}

\subsection{Production and Recovery of Levan at Different $p H$ Values}

G. albidus TMW 2.1191 isolated from water-kefir $[8,20]$ was used for the production and recovery of levan. Cells were generally incubated in $500 \mathrm{~mL}$ Erlenmeyer flasks, which were filled with $50 \mathrm{~mL}$ liquid medium to facilitate aerobic growth on a rotary shaker. At first, G. albidus was grown overnight (o/n) at $200 \mathrm{rpm}$ and $30^{\circ} \mathrm{C}$ in a liquid NaG-medium consisting of $20 \mathrm{~g} / \mathrm{L}$ sodium gluconate, $3 \mathrm{~g} / \mathrm{L}$ yeast extract, $2 \mathrm{~g} / \mathrm{L}$ peptone, $3 \mathrm{~g} / \mathrm{L}$ glycerol, $10 \mathrm{~g} / \mathrm{L}$ mannitol, $3 \mathrm{~g} / \mathrm{L}$ glucose (initial $\mathrm{pH}$ adjusted to 6.0) until an $\mathrm{OD}_{600}$ in the range of 2.0-3.0 was reached. Cells were then harvested by centrifugation $(7000 \times g)$ and resuspended in $50 \mathrm{~mL}$ of $0.1 \mathrm{M}$ buffers ( $\mathrm{pH}$ 3.5: citric acid/ $\mathrm{Na}_{2} \mathrm{HPO}_{4} ; \mathrm{pH}$ 4.0-5.5: Na-acetate/acetic acid; $\mathrm{pH}$ 6.0: $\mathrm{Na}_{2} \mathrm{HPO}_{4} / \mathrm{NaH}_{2} \mathrm{PO}_{4}$ ). For efficient levansucrase release, these buffers were supplemented with $0.1 \mathrm{M}$ sucrose and incubated for $3 \mathrm{~h}$ at $30^{\circ} \mathrm{C}$ and $200 \mathrm{rpm}[27,28]$. Afterwards, cells were separated by centrifugation $(7000 \times g)$ and discarded. The supernatants were collected, diluted 1:1 with the same (unfermented) buffer initially used for the levansucrase release (+0.1 M sucrose) and statically incubated for total levan production at six different $\mathrm{pH}$ values $\left(24 \mathrm{~h}, 30^{\circ} \mathrm{C}\right)$. Finally, levan samples were dialyzed (MWCO: $3.5 \mathrm{kDa}$ ) against $\mathrm{ddH}_{2} \mathrm{O}\left(4^{\circ} \mathrm{C} ; 48 \mathrm{~h}\right)$ for removal of sugars and fructooligosaccharides $<3.5 \mathrm{kDa}$, lyophilized and weighed. For fermentative levan production without $\mathrm{pH}$ control, G. albidus was cultivated for $48 \mathrm{~h}$ in NaG medium containing $80 \mathrm{~g} / \mathrm{L}$ sucrose as the sole sugar source. After centrifugation and discarding of cells, the supernatant was treated with two volumes of chilled ethanol to precipitate the formed levan from the fermentation broth. The precipitates were collected by centrifugation $\left(10,000 \times g, 10 \mathrm{~min}, 4{ }^{\circ} \mathrm{C}\right)$, re-dissolved in $\mathrm{ddH}_{2} \mathrm{O}$, dialyzed against $\mathrm{ddH}_{2} \mathrm{O}(\mathrm{MWCO}$ : $3.5 \mathrm{kDa} ; 4^{\circ} \mathrm{C} ; 48 \mathrm{~h}$ ) and lyophilized. The nitrogen contents of the levan samples isolated from $\mathrm{NaG}$ medium and of the levans isolated from Na-acetate buffers $(\mathrm{pH} 4.0+5.0)$ were determined using the Dumas method (DUMATHERM ${ }^{\circledR}$ CN, C. Gerhardt GmbH \& Co KG, Deutschland).

\subsection{Separation and Size Determinations of Levan Fractions}

The molecular weights and root mean square (rms) radii of the recovered levans were determined by asymmetric flow field-flow fractionation (AF4; Eclipse Dualtec, Wyatt Technology, Santa Barbara, CA, USA) coupled with multi-angle laser-light scattering (MALLS) (Dawn EOS, Wyatt Technology, Santa Barbara, CA, USA) analysis and UV detection (Dionex Ultimate 3000, Thermo Fisher Scientific, Waltham, MA, USA). The lyophilized levan was initially dissolved in $\mathrm{ddH}_{2} \mathrm{O}$ to a final concentration of $0.1 \mathrm{mg} / \mathrm{mL}$. A quantity of $100 \mu \mathrm{L}$ of the respective sample $(10 \mu \mathrm{g})$ was then injected into the separation channel, equipped with a $10 \mathrm{kDa}$ cellulose membrane (Nadir regenerated cellulose). Separations were performed using a detector-flow rate of $1 \mathrm{~mL} / \mathrm{min}$ and a crossflow gradient of 3 to $0.1 \mathrm{~mL} / \mathrm{min}$ over $15 \mathrm{~min}$, followed by $15 \mathrm{~min}$ of a steady crossflow of $0.1 \mathrm{~mL} / \mathrm{min}$. All chromatograms were analyzed with the software ASTRA 5 (Wyatt Technologies, Santa Barbara, CA, USA) using a dn/dc value of $0.146 \mathrm{~mL} / \mathrm{g}$ [20] and the Berry model integrated in the ASTRA software. The extinction coefficients 
$(\lambda=400 \mathrm{~nm})$ of levans produced at different $\mathrm{pH}$ values were determined in $1 \mathrm{~mL}$ cuvettes and a Novaspec Plus spectrophotometer (Amersham plc, Little Chalfont, UK).

\subsection{Rheological Measurements}

Prior to rheological measurements, levan samples were dissolved in $\mathrm{ddH}_{2} \mathrm{O}$. Solutions with high viscosity were centrifuged for $1 \mathrm{~min}$ at $1000 \mathrm{~g}$ to remove air bubbles. Steady and dynamic rheological measurements were carried out with a Physica MCR 501 rheometer (Anton Paar, Graz, Austria) at a constant temperature of $20^{\circ} \mathrm{C}$. A double-gap geometry (DG26.7-SS, Anton Paar, Graz, Austria) was used for measurements at low viscosities (levan produced in buffers with a $\mathrm{pH} \leq 4$, levan produced in buffer with a $\mathrm{pH}>4$ and $\leq 5 \%(w / v)$, levan isolated from NaG-medium $\leq 10 \%$ $(w / v))$. A cone-plate geometry (CP 50-1, Anton Paar, Graz, Austria) was used for measurements above these concentrations. Steady-shear rheological data for each levan were obtained at a concentration of $5 \%(w / v)$. In addition, the viscosity curves of levan produced in buffers ( $\mathrm{pH} 4.0,5.0$ and 6.0) and levan isolated from NaG-medium were recorded in the concentration range between 1-10\% $(w / v)$ and $1-25 \%(w / v)$, respectively. The viscosity curves were measured from $0.1 \mathrm{~s}^{-1}$ to $1000 \mathrm{~s}^{-1}$ followed by a reverse sequence from $1000 \mathrm{~s}^{-1}$ to $0.1 \mathrm{~s}^{-1}$. Five viscosity values were recorded per order of magnitude over a period of $10 \mathrm{~s}$ using a logarithmic scale. In order to determine the viscoelastic properties of levan produced at $\mathrm{pH} 4.0,5.0$ and 6.0, dynamic-rheological measurements were carried out at a concentration of $10 \%(w / v)$. In addition, a concentration of $5 \%(w / v)$ was measured for levan pH 5.0 and a concentration of $15 \%(w / v)$ for levan $\mathrm{pH} 4.0$. Strain-sweep tests (stress range $0.1-100 \%)$ were performed at an angular frequency of $1 \mathrm{rad} / \mathrm{s}$ to determine the linear viscoelastic (LVE) region at $10 \%$ $(w / v)$. Frequency-sweep tests (angular frequency 0.1-100 rad/s) were carried out in the LVE regime, at constant strain $(1.0 \%)$. All rheological measurements were carried out in triplicate.

\subsection{Determination of the Degree of Branching}

Methylation analysis was carried out as described by Fels et al. [12], with some modifications. Briefly, levans were methylated in DMSO by using powdered sodium hydroxide and methyl iodide. Subsequently, methylated polysaccharides were recovered by extraction with dichloromethane. Due to the very low stability of fructans under acidic conditions, modified hydrolysis conditions $(1 \mathrm{M}$ trifluoroacetic acid, $70{ }^{\circ} \mathrm{C}, 30 \mathrm{~min}$ ) were used [29]. After reduction with sodium borodeuteride and acetylation with acetic anhydride, the resulting partially-methylated alditol acetates were identified by GC-MS and semi-quantitatively determined by GC-FID. The FID response factors for terminal glucose, 1,3-linked glucose, and 1,3,6-linked glucose units described by Sweet et al. [30] were used for terminal fructose, 2,6-linked fructose, and 1,2,6-linked fructose units. NMR spectroscopy was carried out on an Ascend $500 \mathrm{MHz}$ NMR spectrometer after dissolving the levans in $\mathrm{D}_{2} \mathrm{O}$.

\section{Results}

\subsection{Amounts and Sizes of the Produced Levans}

Different amounts of levan were produced in buffers of different initial $\mathrm{pH}$ (Figure 1 ). The maximum levan amount could be recovered at $\mathrm{pH}$ 5.0. At $\mathrm{pH} 3.5$, a significant decrease in levan production could be detected. Upon the growth of G. albidus TMW 2.1191 in NaG medium containing $80 \mathrm{~g} / \mathrm{L}$ sucrose as the sole sugar source, $31.4 \pm 2.3 \mathrm{~g} / \mathrm{L}$ of levan could be isolated from the fermentation broth. The isolated levans were further subjected to AF4-MALLS-UV analysis (Figure 2). The lower the $\mathrm{pH}$ of the used buffers, the earlier the levan fractions eluted (Figure 2A). The levan isolated from $\mathrm{NaG}$ medium eluted distinctly earlier than the other levan samples. The molar masses and geometric radii of the levans were higher if the levan fractions eluted later, revealing an increasing hydrodynamic volume of the levan molecules with increasing molecular weight (Figure 2C,D). Moreover, the extinctions $(\lambda=400 \mathrm{~nm})$ of the levans increased with rising production $\mathrm{pH}$ and molecule size (Figure 2B). The molar mass distribution of the levan isolated from $\mathrm{NaG}$ medium could not be evaluated as no usable 
UV concentration signals were obtained, even if ten-times the amount of levan $(100 \mu \mathrm{g})$ had been injected into the separation channel.

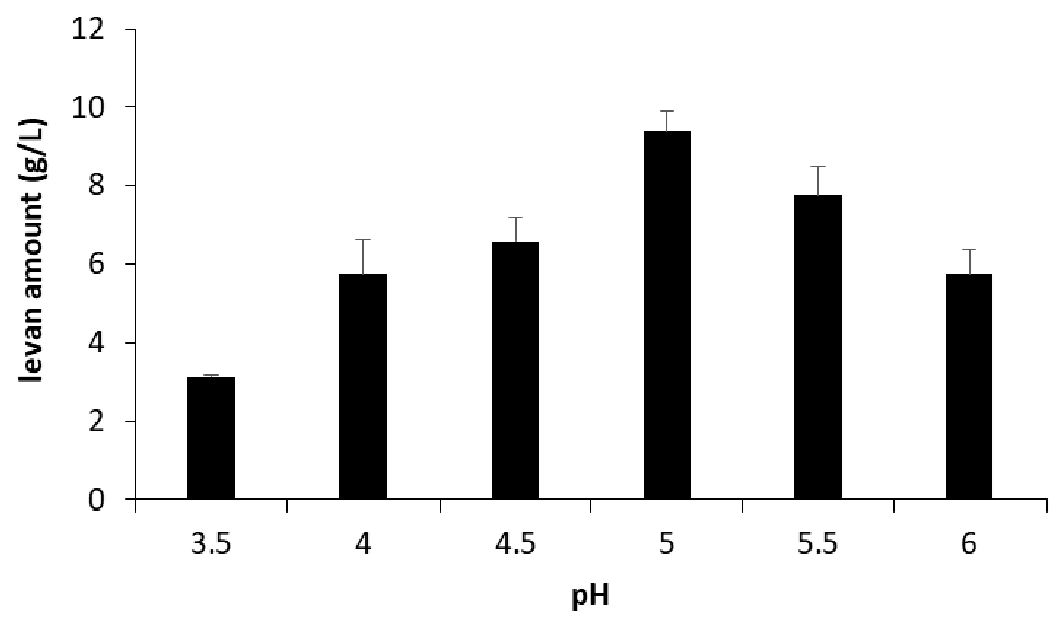

Figure 1. Levan amounts produced at different $\mathrm{pH}$ conditions in buffers. G. albidus TMW 2.1191 was first cultivated for $3 \mathrm{~h}$ at $30^{\circ} \mathrm{C}$ in six buffers ( $\mathrm{pH}$ 3.5-6.0), which contained $0.1 \mathrm{M}$ sucrose, respectively, for release of its levansucrase (accession number: AQS91558) according to Jakob (2014) [26]. The obtained cell-free levan and enzyme-containing supernatants were then diluted 1:1 with the same buffer initially used for levansucrase release for the total production of levan at different $\mathrm{pH}\left(30^{\circ} \mathrm{C}, 24 \mathrm{~h}\right)$.
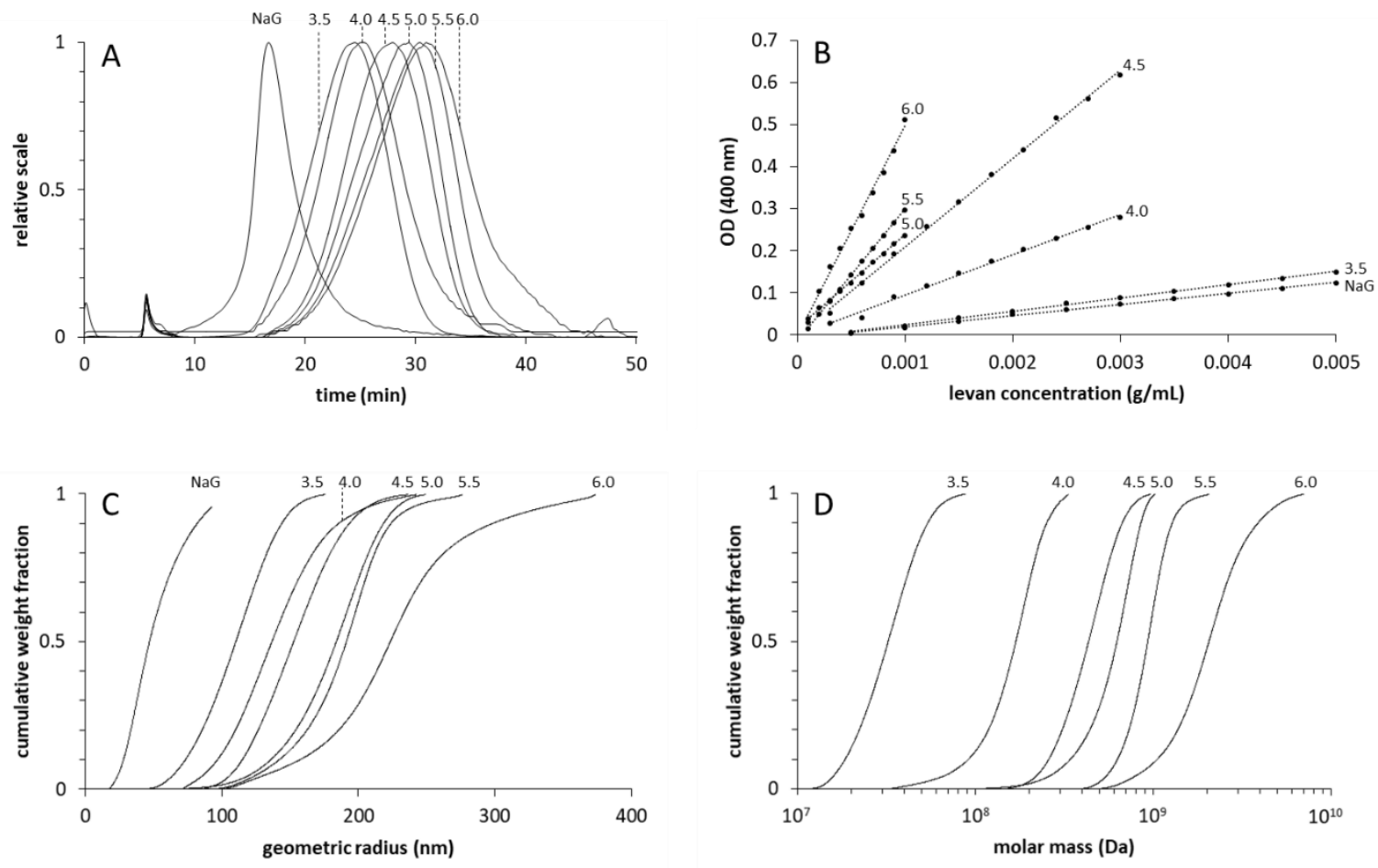

Figure 2. Elution profiles (light-scattering detector $\left.11,90^{\circ}\right)(\mathbf{A})$, extinction coefficients at $\lambda=400 \mathrm{~nm}$ (B), cumulative distributions of geometric radii (C) and of molar masses (D) of levans produced at different $\mathrm{pH}(3.5-6.0)$ in buffers and in $\mathrm{NaG}$ medium.

\subsection{Rheological and Structural Properties of the Produced Levans}

At first, concentration-dependent viscosity curves were recorded for the levans produced at $\mathrm{pH}$ 4.0, 5.0, 6.0, and the levan isolated from NaG-medium (Figure 3). A shear-thinning behavior was observed for levans $\mathrm{pH} 4.0 / 5.0 / 6.0$ at specific concentrations $\geq 3 \%(w / v)$ (Figure 3A-C). Levans 
produced at $\mathrm{pH} 5.0$ and $\mathrm{pH} 6.0$ showed almost identical viscosity-curve profiles with a sharp increase in viscosity and more pronounced shear-thinning behavior between $4 \%(w / v)$ and $5 \%(w / v)$. The levan produced at $\mathrm{pH} 4.0$ exhibited a significantly lower viscosity that increased more evenly with the polymer concentration. While the zero shear viscosities of levans $\mathrm{pH}$ 5.0/6.0 at polymer concentrations of $4 \%(w / v)$ were $\sim 10$ times higher than that of levan $\mathrm{pH} 4.0$ (Figure $3 \mathrm{~A}-\mathrm{C}$ ), the viscosity of levans $\mathrm{pH}$ 5.0/6.0 (shear rate $0.11 / \mathrm{s}$ ) was $~ 100$ times and $~ 1000$ times higher at polymer concentrations of $5 \%$ $(w / v)$ and $6 \%(w / v)$, respectively. On the contrary, no shear-thinning behavior and no distinct viscosity increase could be detected for the levan isolated from $\mathrm{NaG}$ medium, even if a specific concentration of $25 \%(w / v)$ had been applied (Figure 3D). As the levan produced at $\mathrm{pH} 4.0$ differed distinctly regarding its viscosity and flow behavior from levans produced at $\mathrm{pH} \geq 4.5$ (Figure $3 \mathrm{~A}-\mathrm{C}$ ), oscillatory-shear experiments were additionally performed (Figure 4).
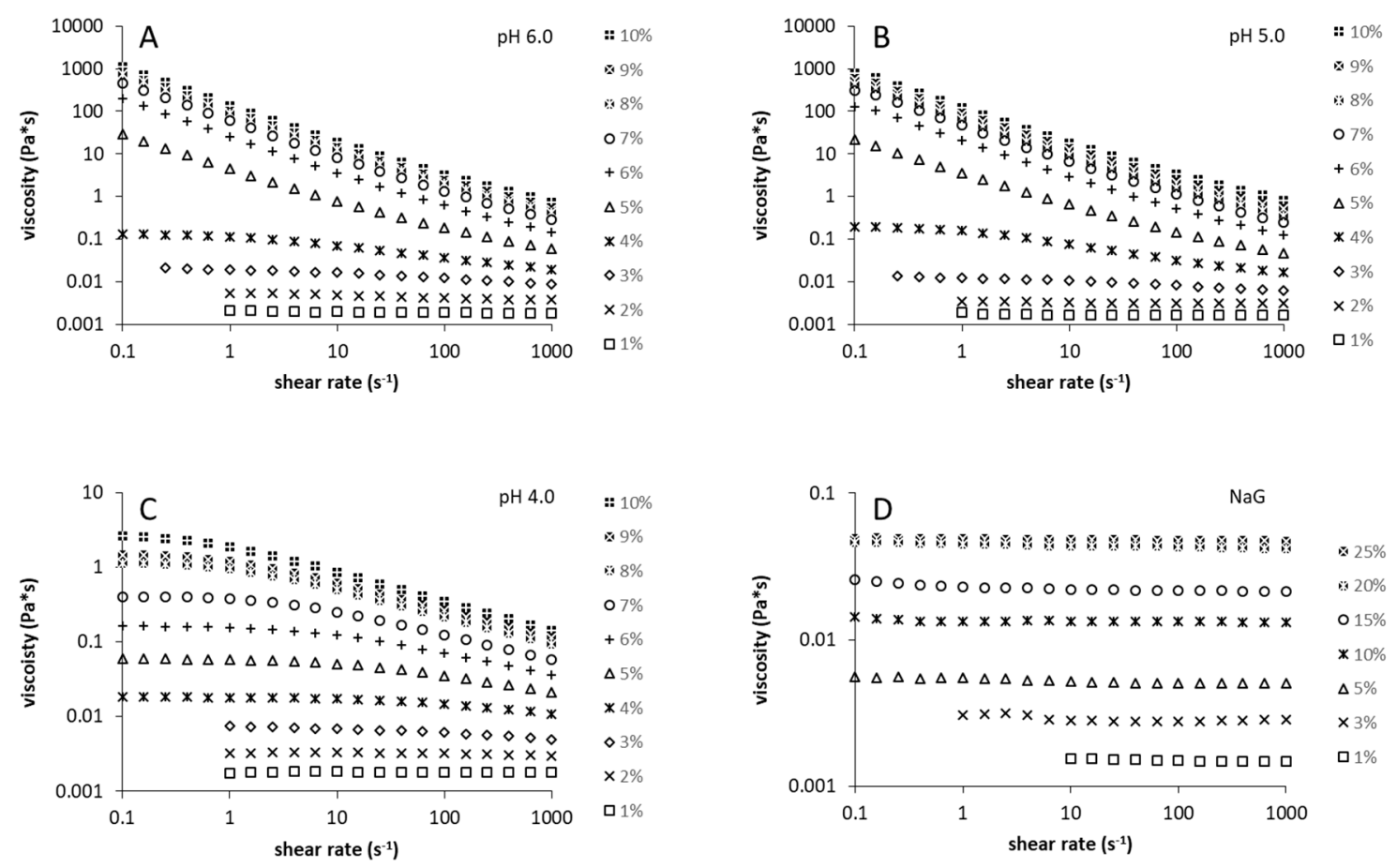

Figure 3. Concentration-dependent viscosity curves of levans produced at $\mathrm{pH} 6.0$ (A), $\mathrm{pH} 5.0$ (B), $\mathrm{pH} 4.0$ (C) and in $\mathrm{NaG}$ medium (D) recorded at $20^{\circ} \mathrm{C}$, respectively. Noisy data obtained at low shear rates and concentrations are not depicted.
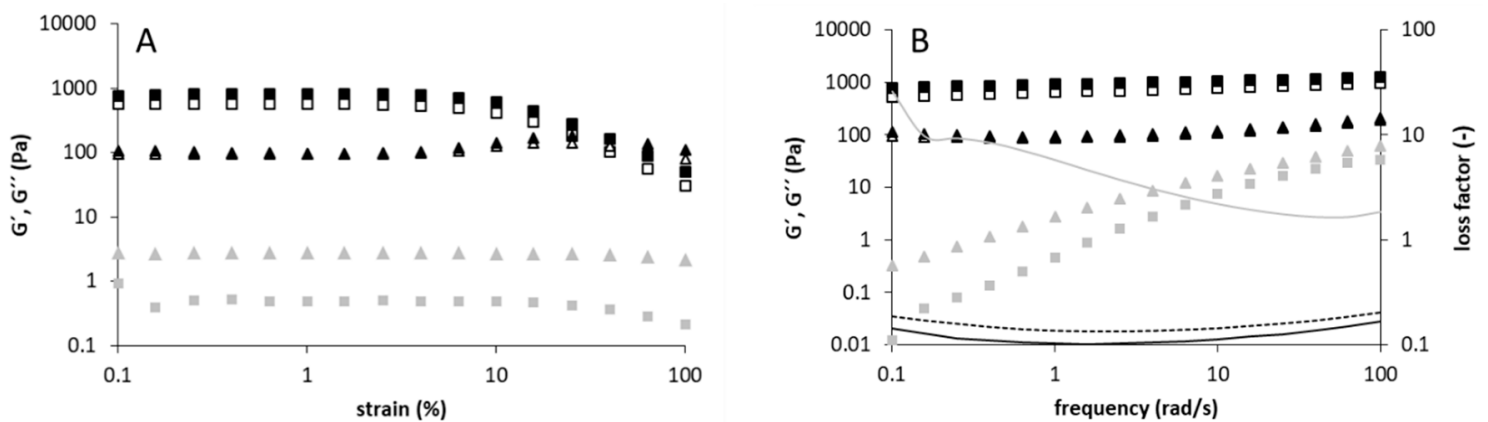

Figure 4. Strain-sweep test (A) and frequency-sweep test (B) of levans produced at pH 6.0 (black), $\mathrm{pH} 5.0$ (white) and $\mathrm{pH} 4.0$ (grey). Data were recorded at $20^{\circ} \mathrm{C}$ applying a specific concentration of $10 \%$ $(w / v)$. G': square, $\mathrm{G}^{\prime \prime}$ : triangles. Lines represent the loss factor $\left(\tan \delta=\mathrm{G}^{\prime \prime} / \mathrm{G}^{\prime}\right)$ of levans produced at $\mathrm{pH}$ 6.0 (solid, black), pH 5.0 (dotted, black) and pH 4.0 (solid, grey). 
The strain-sweep test (Figure $4 \mathrm{~A}$ ) revealed a fluid-like behavior $\left(\mathrm{G}^{\prime \prime}>\mathrm{G}^{\prime}\right)$ for levan $\mathrm{pH} 4.0(10 \% w / v)$ while a gel-like behavior $\left(G^{\prime \prime}<G^{\prime}\right)$ was observed for levans pH 5.0/6.0 $(10 \% w / v)$. Furthermore, levan pH 4.0 showed a continuous decrease of $G^{\prime}$ and G" (strain thinning) and no crossover of both moduli after reaching the limit of the LVE region, while G" of levans $\mathrm{pH}$ 5.0/6.0 showed a local maximum before both moduli started to decrease (weak-strain overshoot) and finally, crossover. The strain-thinning behavior of levan $\mathrm{pH} 4.0$ is commonly observed for polymer solutions, and is due to the alignment of polymer chains in terms of their flow direction at high strain [31]. The weak-strain overshoot of levans $\mathrm{pH}$ 5.0/6.0 could be explained by the variation of formation and destruction of the network junctions with increasing strain. An increased connectivity of the network up to a certain strain leads to an increased dissipation (maximum of $G^{\prime \prime}$ ), while an increased network disruption at higher strains causes the decrease and the crossover of $G^{\prime}$ and $G^{\prime \prime}$, which indicates a shear-induced phase-transition from gel-like to fluid-like [32].

Levans $\mathrm{pH}$ 5.0/6.0 exhibited a gel-like behavior at a concentration of $10 \%(w / v)$ with $\mathrm{G}^{\prime \prime}<\mathrm{G}^{\prime}$, a slight frequency dependence of both modules and a loss factor $<0.2$ over the tested frequency range (Figure 4B). At 5\% (w/v), levan $\mathrm{pH} 5.0$ also shows a gel-like behavior (Figure S1), but both moduli and the loss factor $(0.19-0.44)$ were more dependent on the frequency at $5 \%$. The levan produced at a $\mathrm{pH}$ of 4.0 showed $\mathrm{G}^{\prime \prime}>\mathrm{G}^{\prime}$ and both modules increased with increasing frequency at a concentration of $10 \%(w / v)$ (Figure 4B) and $15 \%(w / v)$ (Figure S1). The loss factor of levan $\mathrm{pH} 4.0(10 \% w / v)$ decreased from 26 to 1.65 with rising frequency (Figure 4A). Therefore, levan $\mathrm{pH} 4.0$ exhibits the properties of a viscoelastic fluid at $10 \%(w / v)$ in the measured frequency range. To obtain further information about possible structural differences among the rheologically different levans, levans $\mathrm{pH}$ 4.0/5.0/NaG were investigated by two-dimension NMR spectroscopy and methylation analysis (Table 1). The NMR spectra were very similar for all samples and confirmed the presence of levans (data not shown). Methylation analysis allowed for the detection of 2,6-linked and 1,2,6-linked fructose units and thus linear and branched backbone units in all levan samples. The portion of terminal-fructose units was rather high (8.1-13.9\%), however, this may be the result of some lowly abundant low-molecular weight fractions (which were not removed due to interactions with the high-molecular-weight polysaccharides) or modification of levans during the course of the analysis (e.g., partial hydrolysis during sonication). Nevertheless, the relative abundance of 1,2,6-linked fructose units indicates that the levans show a rather low degree of branching. In addition, the ratio between 2,6- and 1,2,6-linked fructose units (26-27) was almost constant for all samples; therefore, the structural analyses suggest that the all levans have a similar structural composition.

Table 1. Glycosidic linkages (mol\%) of levans produced by G. albidus TMW 2.1191 at pH 4.0, pH 5.0, and in NaG medium, as determined by methylation analysis.

\begin{tabular}{cccc}
\hline Glycosidic Linkage & pH 4.0 & pH 5.0 & NaG \\
\hline t-Fruf & $12.3 \pm 3.4$ & $13.9 \pm 1.0$ & $8.1 \pm 0.4$ \\
\hline 2,6-Fruf & $84.6 \pm 3.1$ & $83.1 \pm 1.1$ & $88.5 \pm 0.3$ \\
\hline 1,2,6-Fruf & $3.1 \pm 0.3$ & $3.1 \pm 0.1$ & $3.4 \pm 0.1$ \\
\hline
\end{tabular}

Moreover, the nitrogen content of the structurally analyzed levans (Table 1) was checked using a DUMAS analyzer. The nitrogen content of the levan isolated from $\mathrm{NaG}$ medium was slightly higher $(0.053 \%)$ than that of levans $\mathrm{pH} 4.0 / 5.0(0.010-0.016 \%)$ recovered from sodium acetate buffers.

\section{Discussion}

The yield, size and functional properties of levan from G. albidus TMW 2.1191 can be influenced by modulation of the environmental $\mathrm{pH}$, as demonstrated in the present study and a previous study [20]. Similar findings were obtained for the dextran produced by Lactobacillus hordei TMW 1.1822 [33]. The environmental $\mathrm{pH}$ is, therefore, decisive to trigger the properties of uncharged, water-soluble 
high-molecular-weight exopolysaccharides produced by glucansucrases or fructansucrases [34]. However, it is yet unknown to what extent the size of levan influences its rheological properties. It was previously shown that levans produced by G. albidus TMW 2.1191 without external pH control are comparatively smaller in size at prolonged fermentation times, which might be due to (a combination of continuous acidic hydrolysis, the intrinsic $\beta$-fructosidase activities of levansucrases or possibly additionally expressed $\beta$-fructosidases $[10,20,35,36]$. Accordingly, in the present study, the levan recovered from $\mathrm{NaG}$ medium after $48 \mathrm{~h}$ of incubation exhibited the lowest hydrodynamic volume/radius, at which an elevated nitrogen content was determined for this levan in comparison to the levans produced in Na-acetate buffers ( $\mathrm{pH} 4.0$ and 5.0). The presented approach for levan production in buffers could thus be used and further optimized for the recovery of considerable amounts of pure levans exhibiting different sizes and properties.

A Newton-like flow behavior was observed for the levan produced in $\mathrm{NaG}$ medium up to a specific concentration of 25\% (w/v) (Figure 3D). A similar concentration-dependent flow behavior of levan was found by Kasapis et al. [37] and Arvidson et al. [38] for levans produced by Pseudomonas syringae and Bacillus species, respectively. In their studies, the levans also showed Newtonian flow behavior up to a concentration of $20 \%$ or $30 \%$.

Interestingly, some changes to the rheological properties were detected for levans produced at $\mathrm{pH} \geq 4.0$. At concentrations $\geq 3 \%(w / v)$, these levans showed shear-thinning behavior and a more pronounced increase in viscosity with concentration. Both phenomena are more distinct for levans produced at $\mathrm{pH} \geq 4.5$. Furthermore, levan $\mathrm{pH} 4.0$ behaved like a viscoelastic liquid, while levans produced at $\mathrm{pH}$ 5.0/6.0 showed a gel-like behavior in oscillatory-shear experiments (Figure 4). In the study of Benigar et al. [22], the onset of shear thinning was found between $1.0 \%$ and $4.0 \%$ for three levans of different microbiological origin. In addition, they observed an increasing dependence of viscosity and of shear-thinning behavior on concentration with increasing polymer size. A gel-like behavior comparable to that of levan from G. albidus, produced at $\mathrm{pH}$ 5.0/6.0, could also be found for high-molecular-weight levans from Erwinia amylovora [39] and Brenneria species EniD312 [40].

These results suggest that levan molecules produced by Gluconobacter and other bacteria can interact with each other and build up intermolecular networks if a critical molecular size and a critical polymer concentration is exceeded. These networks may consist of highly entangled high-molecular-weight levan chains. In solutions of levan with low molecular size, the number of entanglement points between different levan chains are likely insufficient to stabilize the physical network. Therefore, these levans ( $\mathrm{pH} 3.5, \mathrm{NaG}$ ) cannot form a physical network and show Newtonian-like flow behavior even at high concentrations. The levan produced at $\mathrm{pH} 4.0$ exhibiting viscoelastic properties could be considered as an intermediate between low-viscosifying $(\mathrm{pH} 3.5, \mathrm{NaG})$ and gel-like levan $(\mathrm{pH} \geq 4.5)$ and might have been composed of some, but too few, levan molecules exhibiting the critical chain length for network formation. Therefore, the homogeneity and polydispersity of a levan fraction also contributes to its functionality. The results from the structural analyses further suggested that the degree of branching was not a decisive factor for the rheological properties in the case of the analyzed levans.

A second model, which might explain the size-dependent rheological behavior of levan, is based on the secondary structure of levan in aqueous solution. With increasing molecular weight, levan transforms from a random coil into a compact spherical molecule, which is increasingly compact/densely packed and turbidity-forming [17,41]. Therefore, Jakob et al. [17] suggested that levan above a certain molecular weight might have the properties of a nanogel particle. Using this comparison, the viscoelastic behavior of levan of a certain size $(\mathrm{pH} \geq 4.0)$ could be explained as the interaction of soft spheres forming a colloidal network [42].

\section{Conclusions}

Our study reveals that the rheological properties of levan are determined by its size and polydispersity, rather than by the amount of levan used or the structural composition. The $\mathrm{pH}$ used during the production of levan can be adjusted to control its size and composition. These findings 
are a key step towards biotechnological exploitation of levan and may help to better understand its functionality in complex (food) matrices and microbial biofilms. In order to gain further insight into the dependence of the functional and rheological properties on its polymer size, the structural degradation of high-molecular-weight levan at high shear rates could be determined to study thixotropy and thus, its viscoelastic behavior at longer time scales.

Supplementary Materials: The following are available online at http://www.mdpi.com/2304-8158/9/2/192/s1, Figure S1: Frequency-sweep test of levans produced at $\mathrm{pH} 5.0$ (white) and pH 4.0 (grey). Data were recorded at $20^{\circ} \mathrm{C}$ applying a specific concentration of $5 \%(w / v)(\mathrm{pH} 5.0)$ and $15 \%(w / v)(\mathrm{pH} 4.0)$. G': square, $\mathrm{G}^{\prime \prime}$ : triangles.

Author Contributions: Conceptualization, C.S.H. and F.J.; Methodology, C.S.H., D.W., F.J.; Supervision, A.B. and F.J.; Funding Acquisition: R.F.V. and F.J.; Writing-Original Draft Preparation, C.S.H., D.W. and F.J.; Writing-Review and Editing, A.B. and R.F.V. All authors have read and agreed to the published version of the manuscript.

Funding: This research was funded by the German Federal Ministry of Food and Agriculture (BMEL) through the Federal Office of Agriculture and Food (BLE), grant number 2816IP001. Open access publishing was funded by the German Research Foundation (DFG) and the Technical University of Munich (TUM) in the framework of the Open Access Publishing Program.

Acknowledgments: We thank Heiko Briesen from the Chair of Process Systems Engineering of the Technical University of Munich (TUM) for the possibility to perform rheological measurements at his institute.

Conflicts of Interest: The authors declare that there is no conflict of interest.

\section{References}

1. Öner, E.T.; Hernández, L.; Combie, J. Review of levan polysaccharide: From a century of past experiences to future prospects. Biotechnol. Adv. 2016, 34, 827-844. [CrossRef]

2. Velázquez-Hernández, M.; Baizabal-Aguirre, V.; Bravo-Patiño, A.; Cajero-Juárez, M.; Chávez-Moctezuma, M.; Valdez-Alarcón, J. Microbial fructosyltransferases and the role of fructans. J. Appl. Microbiol. 2009, 106, 1763-1778. [CrossRef]

3. Kırtel, O.; Lescrinier, E.; Van den Ende, W.; Öner, E.T. Discovery of fructans in Archaea. Carbohydr. Polym. 2019, 220, 149-156. [CrossRef]

4. Van Hijum, S.A.; Bonting, K.; van der Maarel, M.J.; Dijkhuizen, L. Purification of a novel fructosyltransferase from Lactobacillus reuteri strain 121 and characterization of the levan produced. FEMS Microbiol. Lett. 2001, 205, 323-328. [CrossRef]

5. Korakli, M.; Pavlovic, M.; Gänzle, M.G.; Vogel, R.F. Exopolysaccharide and kestose production by Lactobacillus sanfranciscensis LTH2590. Appl. Environ. Microbiol. 2003, 69, 2073-2079. [CrossRef]

6. Tieking, M.; Ehrmann, M.A.; Vogel, R.F.; Gänzle, M.G. Molecular and functional characterization of a levansucrase from the sourdough isolate Lactobacillus sanfranciscensis TMW 1.392. Appl. Microbiol. Biotechnol. 2005, 66, 655-663. [CrossRef]

7. Anwar, M.A.; Kralj, S.; Pique, A.V.; Leemhuis, H.; van der Maarel, M.J.; Dijkhuizen, L. Inulin and levan synthesis by probiotic Lactobacillus gasseri strains: Characterization of three novel fructansucrase enzymes and their fructan products. Microbiology 2010, 156, 1264-1274. [CrossRef]

8. Jakob, F.; Meißner, D.; Vogel, R.F. Comparison of novel GH 68 levansucrases of levan-overproducing Gluconobacter species. Acetic Acid Bact. 2012, 1, e2. [CrossRef]

9. Semjonovs, P.; Shakirova, L.; Treimane, R.; Shvirksts, K.; Auzina, L.; Cleenwerck, I.; Zikmanis, P. Production of extracellular fructans by Gluconobacter nephelii P1464. Lett. Appl. Microbiol. 2016, 62, 145-152. [CrossRef] [PubMed]

10. Jakob, F.; Quintero, Y.; Musacchio, A.; Estrada-de los Santos, P.; Hernández, L.; Vogel, R.F. Acetic acid bacteria encode two levansucrase types of different ecological relationship. Environ. Microbial. 2019, 21, 4151-4165. [CrossRef] [PubMed]

11. Galle, S.; Arendt, E.K. Exopolysaccharides from sourdough lactic acid bacteria. Crit. Rev. Food Sci. Nutr. 2014, 54, 891-901. [CrossRef] [PubMed]

12. Fels, L.; Jakob, F.; Vogel, R.F.; Wefers, D. Structural characterization of the exopolysaccharides from water kefir. Carbohydr. Polym. 2018, 189, 296-303. [CrossRef] [PubMed] 
13. Xu, Q.; Yajima, T.; Li, W.; Saito, K.; Ohshima, Y.; Yoshikai, Y. Levan ( $\beta-2,6$-fructan), a major fraction of fermented soybean mucilage, displays immunostimulating properties via Toll-like receptor 4 signalling: Induction of interleukin-12 production and suppression of T-helper type 2 response and immunoglobulin $\mathrm{E}$ production. Clin. Exp. Allergy 2006, 36, 94-101. [PubMed]

14. Shih, I.-L.; Yu, Y.-T.; Shieh, C.-J.; Hsieh, C.-Y. Selective production and characterization of levan by Bacillus subtilis (Natto) Takahashi. J. Agric. Food Chem. 2005, 53, 8211-8215. [CrossRef] [PubMed]

15. Kang, S.A.; Jang, K.-H.; Seo, J.-W.; Kim, K.H.; Kim, Y.H.; Rairakhwada, D.; Seo, M.Y.; Lee, J.O.; Ha, S.; Kim, C. Levan: Applications and perspectives. In Microbial Production of Biopolymers and Polymer Precursors: Applications and Perspectives; Caister Academic Press: Norfolk, UK, 2009; pp. 145-161.

16. Jakob, F.; Steger, S.; Vogel, R.F. Influence of novel fructans produced by selected acetic acid bacteria on the volume and texture of wheat breads. Eur. Food Res. Technol. 2012, 234, 493-499. [CrossRef]

17. Jakob, F.; Pfaff, A.; Novoa-Carballal, R.; Rübsam, H.; Becker, T.; Vogel, R.F. Structural analysis of fructans produced by acetic acid bacteria reveals a relation to hydrocolloid function. Carbohydr. Polym. 2013, 92, 1234-1242. [CrossRef] [PubMed]

18. Ua-Arak, T.; Jakob, F.; Vogel, R.F. Characterization of growth and exopolysaccharide production of selected acetic acid bacteria in buckwheat sourdoughs. Int. J. Food Microbiol. 2016, 239, 103-112. [CrossRef]

19. Ua-Arak, T.; Jakob, F.; Vogel, R.F. Influence of levan-producing acetic acid bacteria on buckwheat-sourdough breads. Food Microbiol. 2017, 65, 95-104. [CrossRef]

20. Ua-Arak, T.; Jakob, F.; Vogel, R.F. Fermentation $\mathrm{pH}$ modulates the size distributions and functional properties of Gluconobacter albidus TMW 2.1191 levan. Front. Microbiol. 2017, 8, 807. [CrossRef]

21. Dogsa, I.; Brloznik, M.; Stopar, D.; Mandic-Mulec, I. Exopolymer diversity and the role of levan in Bacillus subtilis biofilms. PLoS ONE 2013, 8, e62044. [CrossRef]

22. Benigar, E.; Dogsa, I.; Stopar, D.; Jamnik, A.; Cigić, I.K.; Tomšič, M. Structure and dynamics of a polysaccharide matrix: Aqueous solutions of bacterial levan. Langmuir 2014, 30, 4172-4182. [CrossRef]

23. Stojković, B.; Sretenovic, S.; Dogsa, I.; Poberaj, I.; Stopar, D. Viscoelastic properties of levan-DNA mixtures important in microbial biofilm formation as determined by micro-and macrorheology. Biophys. J. 2015, 108, 758-765. [CrossRef] [PubMed]

24. Benigar, E.; Zupančič Valant, A.; Dogsa, I.; Sretenovic, S.; Stopar, D.; Jamnik, A.; Tomšič, M. Structure and dynamics of a model polymer mixture mimicking a levan-based bacterial biofilm of Bacillus subtilis. Langmuir 2016, 32, 8182-8194. [CrossRef] [PubMed]

25. Laue, H.; Schenk, A.; Li, H.; Lambertsen, L.; Neu, T.R.; Molin, S.; Ullrich, M.S. Contribution of alginate and levan production to biofilm formation by Pseudomonas syringae. Microbiology 2006, 152, 2909-2918. [CrossRef]

26. Koczan, J.M.; McGrath, M.J.; Zhao, Y.; Sundin, G.W. Contribution of Erwinia amylovora exopolysaccharides amylovoran and levan to biofilm formation: Implications in pathogenicity. Phytopathology 2009, 99, 1237-1244. [CrossRef]

27. Jakob, F. Novel Fructans from Acetic Acid Bacteria; Technische Universität München: Munich, Germany, 2014.

28. Jakob, F.; Vogel, R.F. Method for Producing Exopolysaccharides, Products and Uses Thereof; Google Patents: Mountain View, CA, USA, 2015.

29. Carpita, N.C.; Housley, T.L.; Hendrix, J.E. New features of plant-fructan structure revealed by methylation analysis and carbon-13 NMR spectroscopy. Carbohydr. Res. 1991, 217, 127-136. [CrossRef]

30. Sweet, D.P.; Shapiro, R.H.; Albersheim, P. Quantitative analysis by various GLC response-factor theories for partially methylated and partially ethylated alditol acetates. Carbohydr. Res. 1975, 40, 217-225. [CrossRef]

31. Hyun, K.; Kim, S.H.; Ahn, K.H.; Lee, S.J. Large amplitude oscillatory shear as a way to classify the complex fluids. J. Non-Newton. Fluid Mech. 2002, 107, 51-65. [CrossRef]

32. Hyun, K.; Wilhelm, M.; Klein, C.O.; Cho, K.S.; Nam, J.G.; Ahn, K.H.; Lee, S.J.; Ewoldt, R.H.; McKinley, G.H. A review of nonlinear oscillatory shear tests: Analysis and application of large amplitude oscillatory shear (LAOS). Prog. Polym. Sci. 2011, 36, 1697-1753. [CrossRef]

33. Schmid, J.; Bechtner, J.; Vogel, R.F.; Jakob, F. A systematic approach to study the pH-dependent release, productivity and product specificity of dextransucrases. Microb. Cell Fact. 2019, 18, 1-8. [CrossRef]

34. Hundschell, C.S.; Wagemans, A.M. Rheology of Common Uncharged Exopolysaccharides for Food Applications. Curr. Opin. Food Sci. 2019, 27, 1-7. [CrossRef] 
35. Runyon, J.R.; Nilsson, L.; Ulmius, M.; Castro, A.; Ionescu, R.; Andersson, C.; Schmidt, C. Characterizing changes in levan physicochemical properties in different $\mathrm{pH}$ environments using asymmetric flow field-flow fractionation. Anal. Bioanal. Chem. 2014, 406, 1597-1605. [CrossRef] [PubMed]

36. Méndez-Lorenzo, L.; Porras-Domínguez, J.R.; Raga-Carbajal, E.; Olvera, C.; Rodríguez-Alegría, M.E.; Carrillo-Nava, E.; Costas, M.; Munguia, A.L. Intrinsic levanase activity of Bacillus subtilis 168 levansucrase (SacB). PLoS ONE 2015, 10, e0143394. [CrossRef] [PubMed]

37. Kasapis, S.; Morris, E.R.; Gross, M.; Rudolph, K. Solution properties of levan polysaccharide from Pseudomonas syringae pv. phaseolicola, and its possible primary role as a blocker of recognition during pathogenesis. Carbohydr. Polym. 1994, 23, 55-64. [CrossRef]

38. Arvidson, S.A.; Rinehart, B.T.; Gadala-Maria, F. Concentration regimes of solutions of levan polysaccharide from Bacillus sp. Carbohydr. Polym. 2006, 65, 144-149. [CrossRef]

39. Peng, J.; Xu, W.; Ni, D.; Zhang, W.; Zhang, T.; Guang, C.; Mu, W. Preparation of a novel water-soluble gel from Erwinia amylovora levan. Int. J. Biol. Macromol. 2019, 122, 469-478. [CrossRef]

40. Xu, W.; Liu, Q.; Bai, Y.; Yu, S.; Zhang, T.; Jiang, B.; Mu, W. Physicochemical properties of a high molecular weight levan from Brenneria sp. EniD312. Int. J. Biol. Macromol. 2018, 109, 810-818. [CrossRef]

41. Hundschell, C.S.; Jakob, F.; Wagemans, A.M. Molecular Weight Dependent Structure and Polymer Density of the Exopolysaccharide Levan. arXiv 2019, arXiv:1909.07737.

42. Senff, H.; Richtering, W. Temperature sensitive microgel suspensions: Colloidal phase behavior and rheology of soft spheres. J. Chem. Phys. 1999, 111, 1705-1711. [CrossRef]

(C) 2020 by the authors. Licensee MDPI, Basel, Switzerland. This article is an open access article distributed under the terms and conditions of the Creative Commons Attribution (CC BY) license (http://creativecommons.org/licenses/by/4.0/). 